\title{
BMJ Open Prevalence of pregnancy-related complications and course of labour of surviving women who gave birth in selected health facilities in Rwanda: a health facility-based, cross- sectional study
}

\author{
Jean Paul Semasaka Sengoma, ${ }^{1,2}$ Gunilla Krantz, ${ }^{3}$ Manasse Nzayirambaho, ${ }^{2}$
} Cyprien Munyanshongore, ${ }^{2}$ Kristina Edvardsson,, ${ }^{1,4}$ Ingrid Mogren ${ }^{1}$

To cite: Semasaka Sengoma JP, Krantz G, Nzayirambaho M, et al. Prevalence of pregnancy-related complications and course of labour of surviving women who gave birth in selected health facilities in Rwanda: a health facility-based, crosssectional study. BMJ Open 2017;7:e015015. doi:10.1136/ bmjopen-2016-015015

- Prepublication history for this paper is available online. To view these files please visit the journal online (http://dx.doi org/10.1136/bmjopen-2016015015).

Received 4 November 2016 Revised 19 April 2017 Accepted 10 May 2017

CrossMark

For numbered affiliations see end of article.

Correspondence to Dr Jean Paul Semasaka Sengoma; jeanpaul.semasaka. sengoma@umu.se

\section{ABSTRACT}

Objectives This study estimated health facility-based prevalence for pre-eclampsia/eclampsia, postpartum haemorrhage and caesarean section (CS) due to prolonged labour/dystocia. The background characteristics of Rwandan pregnant women, the course of labour and the level of healthcare were investigated in relation to pregnancy and delivery outcomes.

Methods This is health facility-based study and data were collected in 2014-2015 through structured interviews and medical records $(\mathrm{n}=817)$ in Kigali and Northern Province, Rwanda. Frequencies and prevalence were used to describe participants' background factors, labour and deliveryrelated characteristics. Bivariable and multivariable logistic regression models were performed for different background factors and pregnancy/delivery outcomes.

Results Pre-eclampsia/eclampsia, postpartum haemorrhage and CS due to prolonged labour/dystocia represented $1 \%$, $2.7 \%$ and $5.4 \%$ of all participants, respectively. In total, $56.4 \%$ of the participants were transferred from facilities with low levels to those with higher levels of healthcare, and the majority were transferred from health centres to district hospitals, with CS as the main reason for transfer. Participants who arrived at the health facility with cervical dilation grade of $\leq 3 \mathrm{~cm}$ spent more hours in maternity ward than those who arrived with cervical dilatation grade of $\geq 4 \mathrm{~cm}$. Risk factors for CS due to prolonged labour or dystocia were poor households, nulliparity and residence far from health facility.

Conclusions The estimated health facility-based prevalence of pregnancy-related complications was relatively low in this sample from Rwanda. CS was the main reason for the transfer of pregnant women from health centres to district hospitals. Upgrading the capacity of health centres in the management of pregnant women in Rwanda may improve maternal and fetal health.

\section{BACKGROUND}

Some pregnancies end tragically with maternal and/or fetal/child death or cause severe maternal and/or child impairment.
Strengths and limitations of this study

- All the women eligible consented to participate in the study.

- Female professional interviewers with nursing and midwifery background who were not working at the selected health facilities were employed to make the pregnant women feel comfortable while responding to questions.

- There may also be under-reporting of cases and physicians' diagnosis of pregnancy-related complications because of not following the preestablished guidelines. This can happen due to insufficient knowledge or misinterpretation or lack of time due to heavy workloads and lack of the equipment necessary for management of complicated pregnancies.

- Due to a lack of knowledge in seasonal variation of the investigated pregnancy-related complications in Rwanda, the study design did not take into account a possible seasonal variation in outcomes. This may be a potential limitation, because the outcomes during the study period may not be representative of a whole year.

- The study design focused on women who survived pregnancy and childbirth and did not take into account women who had died from pregnancyrelated complications. This may have resulted in minor underestimation of cases.

In 2013, about 300000 maternal deaths occurred worldwide, and every year more than one and half million women suffer from pregnancy-related complications during pregnancy and delivery. ${ }^{2}{ }^{3}$ The most common pregnancy-related complications are maternal haemorrhage, maternal sepsis, abortion, hypertensive disorders (pre-eclampsia, eclampsia and pregnancy-induced 
hypertension) and obstructed labour. ${ }^{45}$ Maternal haemorrhage is the leading cause of maternal mortality, representing $33.9 \%$ of all maternal deaths in Africa. The prevalence of post-partum haemorrhage (PPH) in the world is approximately $6 \% .^{5}$ In Uganda, between 2013 and 2014, the incidence of PPH was 9\%, while the prevalence of maternal haemorrhage was estimated to be around $19.3 \%$ in Rwandan referral hospitals. ${ }^{5-7}$ According to the WHO, hypertensive disorders during pregnancy account for $9 \%$ of maternal mortality in Africa and Asia. ${ }^{5}$ Pre-eclampsia, characterised by hypertension and proteinuria, complicates 3\%-5\% of pregnancies worldwide. ${ }^{8}$ Pre-eclampsia can develop into eclampsia, characterised by the seizures that may be fatal for both mother and fetus. ${ }^{9}$ In 2013, the prevalence of pre-eclampsia/eclampsia in the East African region (ie, Democratic Republic of Congo, Kenya and Uganda) was $1.02 \%, 2.27 \%$ and $1.15 \%$, respectively. ${ }^{10}$

Prolonged labour or obstructed labour occurs when the fetus does not progress into the birth canal despite strong uterine contractions. ${ }^{11}$ Obstructed labour represents $8 \%$ of maternal deaths globally. ${ }^{1}$ In 2010 , the incidence of obstructed labour was around $12.2 \%$ in Ethiopia and $3.7 \%$ in Rwanda in 2011. ${ }^{12} 13$

During the last decade, Rwanda has made significant improvements in maternal health. ${ }^{14}$ In 2015, Rwanda reported a maternal mortality ratio of 210 per 100000 live births and is one of few African countries that has managed to fulfil the fifth Millennium Development Goal of reducing maternal mortality by over $75 \%$ between 1990 and 2015. ${ }^{1516} \mathrm{~A}$ few studies have investigated abortion and postabortion care, antenatal care (ANC), use of community health workers and rapidSMS to promote ANC and childbirth attendance in Rwanda. ${ }^{14} 1718$ However, the literature is limited on the course of labour and pregnancy-related complications.

This study aims to fill the knowledge gap in this area and to serve as documentation for policymakers.

Rwanda's national guidelines on the management of some obstetric and gynaecological common cases are very similar to those of the WHO and thus also similar to those used in many other countries. In these guidelines, pre-eclampsia is defined as blood pressure of $\geq 140 / 90 / 90 \mathrm{~mm}$ $\mathrm{Hg}$ after 20 weeks of gestation plus proteinuria of $300 \mathrm{mg}$ per 24 hours or $>2+$ on a urine dipstick. ${ }^{19}$ Furthermore, eclampsia is defined as the onset of convulsion/generalised seizures in a woman with pre-eclampsia that cannot be attributed to other causes. ${ }^{19} \mathrm{PPH}$ is defined as blood loss of more than $500 \mathrm{ml}$ after vaginal delivery or $1000 \mathrm{ml}$ after caesarean delivery or excessive vaginal bleeding resulting in signs of hypovolemia or a $10 \%$ decline in postpartum haemoglobin concentration from antepartum levels. ${ }^{19}$ Dystocia/prolonged labour is defined as difficult labour or an abnormally slow progression of labour. ${ }^{19}$

This study is part of the Maternal Health Research Programme undertaken by the University of Rwanda in collaboration with University of Gothenburg and Umeå University in Sweden.
AIMS

The study's overall aim was to determine the hospital-based prevalence of pregnancy-related complications (pre-eclampsia/eclampsia, postpartum haemorrhage and prolonged labour or obstructed labour or dystocia labour resulting in a caesarean section (CS) and to describe the course of labour and the background characteristics of women giving birth in selected Rwandan health facilities.

Specific aims were:

- to estimate the hospital-based prevalence of (1) pre-eclampsia and eclampsia, (2) postpartum haemorrhage and (3) prolonged labour or obstructed labour or dystocia labour resulting in a CS;

- to describe the course of labour from the time of arrival at a health facility until delivery and the characteristics related to the course of labour and delivery in relation to the level of healthcare;

- to describe background characteristics of women who give birth in Rwandan health facilities and to describe these characteristics' associations with pregnancy outcomes.

\section{METHODS}

\section{The study setting}

The Rwandan public health system is composed of health posts, health centres, district hospitals, military hospitals, provincial hospitals and referral hospitals. ${ }^{20} \mathrm{~A}$ health centre, which provides the lowest level of healthcare to pregnant women, is where pregnant women with an uncomplicated pregnancy receive healthcare. Complicated cases are referred to higher levels of healthcare, such as district, provincial and referral hospitals. ${ }^{21}$ Health centres are mainly staffed by A2 nurses (registered nurses with secondary levels of education).$^{22}$ Private healthcare is available in Kigali and other large cities in the form of private dispensaries, private clinics and private hospitals. Only the large private hospitals provide assisted delivery. ${ }^{20}$ This study was conducted in the City of Kigali and Northern Province of Rwanda. It involved eight health centres, seven district hospitals, one provincial hospital, one referral hospital and one private hospital.

This study used self-reported data from postpartum women and data from medical records.

This study used diagnoses made by physicians as noted in patients' medical records. The diagnoses were presumed to have been based on definitions and guidelines of pregnancy, labour and delivery-related problems established by the Rwandan Ministry of Health. ${ }^{19}$

\section{Study design and recruitment of study participants}

This was a comprehensive cross-sectional, health facility-based study. During 2013, there were in total 67077 vaginal deliveries in Kigali and Northern Province, and 28786 of these (42\%) occurred in Kigali city and 38292 $(58 \%)$ in Northern Province. Eighteen health facilities $(10 \%)$ with a high number of vaginal deliveries were selected ( 8 health facilities in Kigali and 10 in Northern Province). In Kigali and Northern Province, there are 11 
public hospitals. The nine hospitals selected reported a high number of vaginal deliveries (more than 600) in the year 2013, and the non-selected two hospitals reported less than 600 vaginal deliveries in 2013. We also selected eight health centres from all eight districts of Kigali and Northern Province that reported high number of deliveries in 2013 and included one private hospital. The sample size of 817 women was calculated based on the estimate of the prevalence of CS of $14.8 \%$ in Rwanda in $2013,{ }^{23}$ with an absolute precision of $5 \%$ and with about $10 \%$ of non-response. The target population were women who delivered in the selected health facilities during the data collection (2 December 2014 to 26 January 2015). The number of participants to be selected in each health facility was determined proportionally relative to the number of vaginal deliveries that had occurred in each facility in 2013 (ie, the year before the data collection). This means that health facilities with high numbers of deliveries contributed with higher numbers of selected participants. The heads of the selected health facilities facilitated contact with the heads of their maternity wards. With the support of the heads of maternity wards, delivered women who were about to be discharged were invited to participate in the study. Before the individual interviews, information about the study was provided to the eligible participants. All the invited participants signed a written consent form before their participation in the study. Most of the time, data collection was performed on several occasions (ie, on more than 1 day), in order to reach the quota of participants from each health facility.

\section{Data collection procedures}

A structured questionnaire, which the study team developed, included sociodemographic questions on age, marital status, educational level, previous pregnancies and the last pregnancy. It also asked for information on the outcomes of labour and delivery. The questionnaire was translated from English into Kinyarwanda. The questionnaire was piloted at one non-selected district hospital and its two health centres located in Southern Province, Rwanda. After the pilot study, no major changes were made in the questionnaire; a few adjustments were made in wording to improve clarity. A group of eight experienced interviewers (nurses and midwives) collected data through individual structured interviews under the supervision of the supervisory team of this research (JPSS, MN and $\mathrm{CM}$ ). These data collectors did not work as health professional at any of the selected health facilities during the data collection period. Data entry was performed by three skilled personnel. After the initial data entry, the first author re-registered 81 questionnaires, corresponding to approximately $10 \%$ of the total study sample, each including the 285 variables used in this study, to check the accuracy of the first data entry. The results of this re-registration showed 138 errors, corresponding to an error rate of $0.59 \%$ (138/23 085). The erroneous data were corrected.

\section{Descriptions of variables}

\section{Variables related to pregnancy outcomes}

Binary variables were postpartum haemorrhage and pre-eclampsia/eclampsia; the latter was a combination of the variables pre-eclampsia before labour, eclampsia before labour, pre-eclampsia during labour, eclampsia during labour, pre-eclampsia postpartum and eclampsia post-partum. These variables were collected from medical records from diagnoses made by physicians. The dichotomised variable caesarean section due to prolonged labour or dystocia was created from the variable what was the main indication of caesarean section, and this was collected from medical records.

\section{Variables related to sociodemographic factors}

Maternal age, a continuous numerical variable, was divided into the following categories: $<20$ years, 20-24 years, $25-29$ years, $30-34$ years, $35-39$ years and $\geq 40$ years. Maternal age was also put into three categories, that is, $<25$ years, 25-34 years and $\geq 35$ years. Marital status included married, cohabiting, separated or divorced, widowed and unmarried or single. Marital status was dichotomised into married or cohabitating where the single, divorced or widowed were collectively categorised as the exposure category. Education included never attended school, primary level not completed, primary level completed, vocational training, secondary level not completed, secondary level completed and tertiary level. Education was grouped into three categories: never attended school, completed primary level, completed secondary school or reached tertiary university level. Occupations included student, unskilled worker, skilled worker, civil servant, not employed and other employment; these were dichotomised as employed and non-employed. For each variable about the main health problems during pregnancy, data were collected for the first, second and third trimesters. First trimesterreferred to the first 3 months of the pregnancy. Second trimester referred to 4-6 months of pregnancy. Third trimester referred to 7 months or more. The data on the variables anaemia and hypertension during the first, second and third trimesters were combined as anaemia during pregnancy and hypertension during pregnancy. Hypertension was defined as blood pressure of $\geq 140 / 90 / 90 \mathrm{~mm} \mathrm{Hg} .{ }^{19}$

\section{Variables related to course of labour and delivery}

The binary variables intake of traditional medicines during pregnancy and transfer from another health facility were the only labour and delivery self-reported variables. Other variables were collected from the medical records. Number of hours in maternity ward was a variable calculated using time of admission at the maternity ward and time of delivery. It was categorised into $\leq 4$ hours, $>4-8$ hours, $>8-10$ hours and $>10$ hours. Fetal presentation included cephalic, breech, face, transverse and others. Period when transferred included transferred before labour started and transferred during labour before delivery. Cervical dilation grade at arrival to the hospital and cervical dilation grade at 4 hours in the hospital were continuous numerical variables that were categorised into $\leq 3 \mathrm{~cm}, 4-5 \mathrm{~cm}$ and $\geq 6 \mathrm{~cm}$. 
Table 1 Sociodemographic and reproductive history characteristics of participating women $(n=817)$

\section{Participants (pregnant women)}

\begin{tabular}{|c|c|c|}
\hline Variable & $\begin{array}{l}\text { Mean age } \\
\text { (years) }\end{array}$ & SD* $^{*}$ \\
\hline Mean maternal age & 27.83 & 5.57 \\
\hline $\begin{array}{l}\text { Woman's mean number of years of } \\
\text { education }\end{array}$ & 7.67 & 4.18 \\
\hline Partner mean age (years; SD) & 32.77 & 6.52 \\
\hline \multirow{2}{*}{$\begin{array}{l}\text { Partner's mean number of years of } \\
\text { education (years; SD) }\end{array}$} & 8.97 & 4.23 \\
\hline & $\mathbf{N}$ & $\%$ \\
\hline Maternal age in age group (years) & 816 & 99.0 \\
\hline$<20$ & 46 & 5.6 \\
\hline $20-24$ & 191 & 23.4 \\
\hline $25-29$ & 250 & 30.6 \\
\hline 30-34 & 221 & 27.1 \\
\hline $35-39$ & 90 & 11.0 \\
\hline$\geq 40$ & 18 & 2.2 \\
\hline BMI $^{*}$ calculated & 367 & 44.9 \\
\hline$<18.5$ & 18 & 4.9 \\
\hline $18.5-24.9$ & 240 & 65.4 \\
\hline 25-29.9 & 73 & 19.9 \\
\hline$\geq 30$ & 36 & 9.8 \\
\hline Woman's height (m) & 375 & 45.9 \\
\hline$<1.50$ & 23 & 6.1 \\
\hline$\geq 1.50$ & 352 & 93.9 \\
\hline Woman's weight before pregnancy $(\mathrm{kg})$ & 793 & 97.1 \\
\hline$<50$ & 106 & 13.4 \\
\hline$\geq 50$ & 678 & 86.6 \\
\hline Marital status & 814 & 99.6 \\
\hline Single or unmarried & 70 & 8.6 \\
\hline Widowed & 2 & 0.2 \\
\hline Separated or divorced & 11 & 1.4 \\
\hline Cohabiting & 326 & 40.0 \\
\hline Married & 406 & 49.9 \\
\hline Religion & 814 & 99.6 \\
\hline Catholic & 220 & 27.0 \\
\hline Protestant & 439 & 53.9 \\
\hline Adventist & 92 & 11.3 \\
\hline Islam & 25 & 3.1 \\
\hline Other & 31 & 3.8 \\
\hline None & 7 & 0.9 \\
\hline Education & 815 & 99.8 \\
\hline None & 29 & 3.6 \\
\hline Primary level, not completed & 219 & 26.9 \\
\hline Primary level, completed & 187 & 22.9 \\
\hline Secondary school, not completed & 61 & 7.5 \\
\hline
\end{tabular}

Continued

Table 1 Continued

\section{Participants (pregnant women)}

\begin{tabular}{|lll|}
\hline Variable & $\begin{array}{l}\text { Mean age } \\
\text { (years) }\end{array}$ & SD* $^{*}$ \\
\hline Secondary school, completed & 115 & 14.1 \\
\hline Vocational training & 83 & 10.2 \\
\hline Tertiary, university level & 121 & 14.8 \\
\hline Occupation & $\mathbf{8 0 0}$ & $\mathbf{9 7 . 9}$ \\
\hline Student & 33 & 4.1 \\
\hline Non-skilled worker & 470 & 58.8 \\
\hline Skilled worker & 60 & 7.5 \\
\hline Civil servant & 99 & 12.4 \\
\hline Not employed & 109 & 13.6 \\
\hline Other employment & 29 & 3.6 \\
\hline Number of births (including index birth) & $\mathbf{8 1 6}$ & $\mathbf{9 9 . 9}$ \\
\hline 1 & 335 & 41.1 \\
\hline 2 & 213 & 26.1 \\
\hline 3 & 155 & 19.0 \\
\hline 4 & 78 & 9.6 \\
\hline$\geq 5$ & 35 & 4.3 \\
\hline Number of previous children delivered & $\mathbf{8 1 7}$ & $\mathbf{1 0 0}$ \\
\hline
\end{tabular}
at home

\begin{tabular}{|c|c|c|}
\hline 0 & 756 & 92.5 \\
\hline 1 & 33 & 4.0 \\
\hline 2 & 15 & 1.8 \\
\hline 3 & 8 & 1.0 \\
\hline$\geq 4$ & 5 & 0.6 \\
\hline Number of previous miscarriages & 817 & 100 \\
\hline 0 & 732 & 89.6 \\
\hline 1 & 72 & 8.8 \\
\hline 2 & 10 & 1.2 \\
\hline$\geq 3$ & 3 & 0.4 \\
\hline Woman's HIV status & 817 & 100 \\
\hline Negative & 765 & 93.6 \\
\hline Positive & 52 & 6.4 \\
\hline ANC visits & 817 & 100 \\
\hline Yes & 812 & 99.4 \\
\hline No & 5 & 0.6 \\
\hline Number of ANC visits & 812 & 99.4 \\
\hline 1 visit & 67 & 8.3 \\
\hline 2 visits & 153 & 18.8 \\
\hline 3 visits & 259 & 31.9 \\
\hline 4 visits & 231 & 28.4 \\
\hline$\geq 5$ visits & 102 & 12.6 \\
\hline \multicolumn{3}{|l|}{ Partner to participant } \\
\hline Partner's age in group (years) & 730 & 89.4 \\
\hline$<25$ & 50 & 6.8 \\
\hline
\end{tabular}




\begin{tabular}{|c|c|c|}
\hline \multicolumn{3}{|l|}{ Participants (pregnant women) } \\
\hline Variable & $\begin{array}{l}\text { Mean age } \\
\text { (years) }\end{array}$ & SD* $^{*}$ \\
\hline $25-29$ & 207 & 28.4 \\
\hline 30-34 & 198 & 27.1 \\
\hline 35-39 & 172 & 23.6 \\
\hline$\geq 40$ & 103 & 14.1 \\
\hline Partner's education & 728 & 89.1 \\
\hline None & 35 & 4.8 \\
\hline Primary level, not completed & 119 & 16.3 \\
\hline Primary level, completed & 144 & 19.8 \\
\hline Secondary school, not completed & 44 & 6.0 \\
\hline Secondary school, completed & 164 & 22.5 \\
\hline Vocational training & 84 & 11.5 \\
\hline Tertiary, university level & 138 & 19.0 \\
\hline \multicolumn{3}{|l|}{ Household information } \\
\hline Health insurance & 814 & 99.6 \\
\hline None & 13 & 1.6 \\
\hline Community health-based insurance & 650 & 79.9 \\
\hline $\begin{array}{l}\text { Public insurance (RAMA, MMI, MIS/ } \\
\text { UR) }\end{array}$ & 135 & 16.6 \\
\hline Other private & 16 & 2.0 \\
\hline Household income per month & 772 & 94.5 \\
\hline$<17500$ RWF & 32 & 4.1 \\
\hline 17500-35 999 RWF & 68 & 8.8 \\
\hline 36000-99 999 RWF & 231 & 29.9 \\
\hline 100000-199999 RWF & 213 & 27.6 \\
\hline $200000-499999$ RWF & 163 & 21.1 \\
\hline$>500000$ RWF & 65 & 8.4 \\
\hline $\begin{array}{l}\text { Distance from home to the nearest } \\
\text { health facility }(\mathrm{km})\end{array}$ & 814 & 99.6 \\
\hline$<1$ & 445 & 54.7 \\
\hline $2-5$ & 289 & 35.5 \\
\hline $6-10$ & 64 & 7.9 \\
\hline$\geq 10$ & 16 & 2.0 \\
\hline
\end{tabular}

${ }^{\star} B M I$, body mass index $\left(\mathrm{kg} / \mathrm{m}^{2}\right)$.

ANC, antenatal care; MIS/UR, Medical Insurance of University of Rwanda; MMI,Military Medical Insurance; RAMA, La Rwandaise d'Assurance Maladie.

Number of contractions at arrival and number of contractions/ ten minutes after 4 hours in the hospital included 0, 1, 2, 3 or more contractions. Duration of contractions/ten minutes at arrival to the hospital and duration of contractions at 4 hours in hospital included $\leq 20 \mathrm{~s}, 21-40 \mathrm{~s}$ and $>40 \mathrm{~s}$. Other binary variables were spontaneous rupture of membranes, use of partogram during labour, provision of pharmacological pain relief during labour, artificial rupture of membranes, artificial augmentation of labour with oxytocin, episiotomy done, vacuum extraction and forceps extraction.

\section{Statistical analysis}

Frequency and prevalence ( $\mathrm{n}$ and \%) were used to describe the participants' sociodemographic and reproductive history characteristics, self-reported pregnancy-related problems and delivery-related characteristics, including the features of the course of the labour. Cohen's kappa was calculated to assess agreement between responses from self-reported data and data from medical records.

Pearson's $\chi^{2}$ and Fisher's exact test were used for bivariable analyses. The adjustment for multiple comparisons was made using the Holm-Bonferroni method. ${ }^{24}$ The continuous variable "number of hours in maternity ward' was not normally distributed, so the Wilcoxon test was used to compare medians of the number of hours spent in maternity wards for women who arrived at health facility with a cervical dilation grade of $\leq 3 \mathrm{~cm}$, those who arrived with a cervical dilation of $4-5 \mathrm{~cm}$ and those who arrived with a cervical dilation of $\geq 6 \mathrm{~cm}$. This study identified the factors associated with CS due to prolonged labour/dystocia by using bivariable logistic regression analysis. Statistically significant variables that were associated with CS due to prolonged labour/dystocia were considered for the final logistic regression model. Then a multivariable logistic regression model was built that calculated ORs and their 95\% CIs. In the multivariable model, forward stepwise regression was used, and all statistically significant variables in bivariable analyses were entered one at a time to identify factors associated with CS due to prolonged labour/dystocia. In the final model only factors were kept that were statistically significant $(\mathrm{p}<0.05)$. All multivariable models included parity and women's age for theoretical reasons as other studies have shown these variables to be associated with CS due to prolonged labour/dystocia.

Because no variable was highly correlated $(r \geq 0.40)$, no variable was excluded in the final model. Two dependent variables (PPH and pre-eclampsia/eclampsia) demonstrated a very low number of cases $n=22(2.7 \%)$ and $n=8$ $(1.0 \%)$, respectively, so no further analysis was possible.

\section{ETHICAL CONSIDERATIONS}

Participation in this study was voluntary. Before the interviews, the participants were verbally informed in detail about the aims of the study and the content of the questionnaire. They were ensured about the confidentiality of their responses and reminded that they could withdraw at any time during the interview or thereafter. To ensure confidentiality, the interview was conducted in privacy. All participants signed a written consent form before taking part in the study. This study was conducted according to the guidelines established by the Declaration of Helsinki. ${ }^{25}$ The research protocol and the study questionnaire were approved by the University of Rwanda, College of Medicine and Health Sciences Institutional Review Board (Ref: 010/UR/CMHS/SPH/2014). Before the data collection, authorisation to conduct the study 
Table 2 Prevalence of self-reported pregnancy-related problems in first, second and third trimesters ${ }^{*}$ of pregnancy and the cumulative prevalence $^{\dagger}$

\begin{tabular}{|c|c|c|c|c|c|c|c|c|}
\hline \multirow[t]{2}{*}{ Variable } & \multicolumn{2}{|c|}{ First trimester } & \multicolumn{2}{|c|}{ Second trimester } & \multicolumn{2}{|c|}{ Third trimester } & \multicolumn{2}{|c|}{$\begin{array}{l}\text { Cumulative } \\
\text { prevalence }\end{array}$} \\
\hline & $\mathbf{N}$ & $\%$ & $\mathbf{N}$ & $\%$ & $\mathbf{N}$ & $\%$ & $\mathbf{N}$ & $\%$ \\
\hline Convulsions & 12 & 1.5 & 3 & 0.4 & 3 & 0.4 & 15 & 1.8 \\
\hline Diabetes mellitus & 2 & 0.2 & 1 & 0.1 & 0 & 0 & 2 & 0.2 \\
\hline Severe vaginal bleeding & 30 & 3.7 & 14 & 1.7 & 3 & 0.4 & 46 & 5.6 \\
\hline Abdominal pain and severe bleeding & & & 2 & 0.2 & 4 & 0.5 & 6 & 0.7 \\
\hline Fever & & & 21 & 2.6 & 35 & 4.3 & 50 & 6.1 \\
\hline Leaking of fluid from vagina & & & 52 & 6.4 & 60 & 7.4 & 94 & 11.5 \\
\hline Regular and painful uterine contractions & & & 3 & 0.4 & 26 & 3.2 & 28 & 3.4 \\
\hline
\end{tabular}

${ }^{*}$ The first trimester represents the first 3 months of the pregnancy, the second trimester represents 4-6 months and the third trimester was defined as 7 months or more of pregnancy.

†The third trimester do not include events or complications during delivery.

was obtained from the Ministry of Health in Rwanda (Ref: 20/4029/MCH/2014).

\section{RESULTS}

\section{Sociodemographic and reproductive history characteristics}

In total, 817 women (16-44 years old, with a mean age of 27.8 years) participated in the study. Married women represented $49.9 \%$ of participants, $40.0 \%$ were cohabiting and $8.6 \%$ were single. The proportion of primiparous women was $41.1 \%$, multiparous women with two to four births was $54.7 \%$ and multiparous of more than five births was $4.3 \%$. The frequencies and percentages of sociodemographic and reproductive history characteristics of participants are presented in table 1 .

Cohen's kappa was 0.74 for the agreement between the responses from self-reported data and data from medical records.

\section{Self-reported health problems during pregnancy}

The prevalence of anaemia, severe vaginal bleeding, hypertension and diabetes mellitus during pregnancy was $14.9 \%, 5.6 \%, 5.3 \%$ and $0.2 \%$, respectively. The prevalence of self-reported pregnancy-related health problems during pregnancy are presented in table 2.

\section{Course of labour and delivery and their background characteristics}

Almost three-quarters of the women started labour spontaneously; $5 \%$ had induced labour. In total, $28.4 \%$ of all pregnant women were delivered by CS, including $19.7 \%$ who were delivered by CS before start of labour and 8.7\% who underwent CS during labour (table 3). Table 3 presents the background characteristics related to course of labour and delivery for all the women who started labour spontaneously or whose labour was induced.

For $69 \%$ of the women who underwent CS during labour $(8.7 \%)$, prolonged labour/dystocia was the indication. In total, $56.4 \%$ of the women were transferred from a lower level to a higher level of healthcare and $61.1 \%$ of all the transferred women were in labour. About $68 \%$ of all women who delivered in district hospitals or in referral hospitals were transferred from facilities providing lower levels of care (table 4).

The majority of transferred women $(\mathrm{n}=460 ; 62.4 \%)$ were moved from health centres to a district hospital (figure 1) with 'CS' $(12.5 \%)$, or a scarred uterus $(3.7 \%)$, or to ensure 'better management' (26.7\%) as the main reasons for transferral. A partogram was used during labour for almost all the women who delivered at health centres but was only used by $67 \%$ of the district hospitals (table 4 ). Table 4 presents background characteristics related to course of labour and delivery in relation to the level of healthcare. In total, $44.3 \%$ of pregnant women arrived at a health facility with a cervical dilation grade $\leq 3 \mathrm{~cm}$, $22 \%$ with cervical dilation grade between 4 and $5 \mathrm{~cm}$, and $31.7 \%$ with cervical dilation grade $\geq 6 \mathrm{~cm}$ (figure 1 ). Pregnant women who arrived at a health facility with a cervical dilation grade $\leq 3 \mathrm{~cm}$ spent more hours in maternity ward (median value 9.25 hours; IQR: 3.33-18.50) compared with those who arrived with a cervical dilation grade of $4-5 \mathrm{~cm}$ (median value 5.42 hours; IQR: $1.17-15.00$; $\mathrm{p}<0.001)$ and those who arrived with a cervical dilation grade of $\geq 6 \mathrm{~cm}$ (median value 2.92 hours; IQR: 1.00-6.17; $\mathrm{p}<0.001$ ) (figure 2). 
Table 3 Characteristics of labour and delivery

\section{Variable}

\begin{tabular}{l} 
\\
\hline Intake of traditional medicines during pregnancy ${ }^{\dagger}$ \\
Yes \\
No \\
Transferred from another health facility ${ }^{\dagger}$ \\
Yes \\
No
\end{tabular}

Reason for transfer ${ }^{\dagger}$

Caesarean section

Pre-eclampsia

Prolonged labour/dystocia

Fetal distress

Uterine rupture

Severe bleeding

Other

Reason for transfer from another health facility ${ }^{\ddagger}$

- medical records ${ }^{\ddagger}$

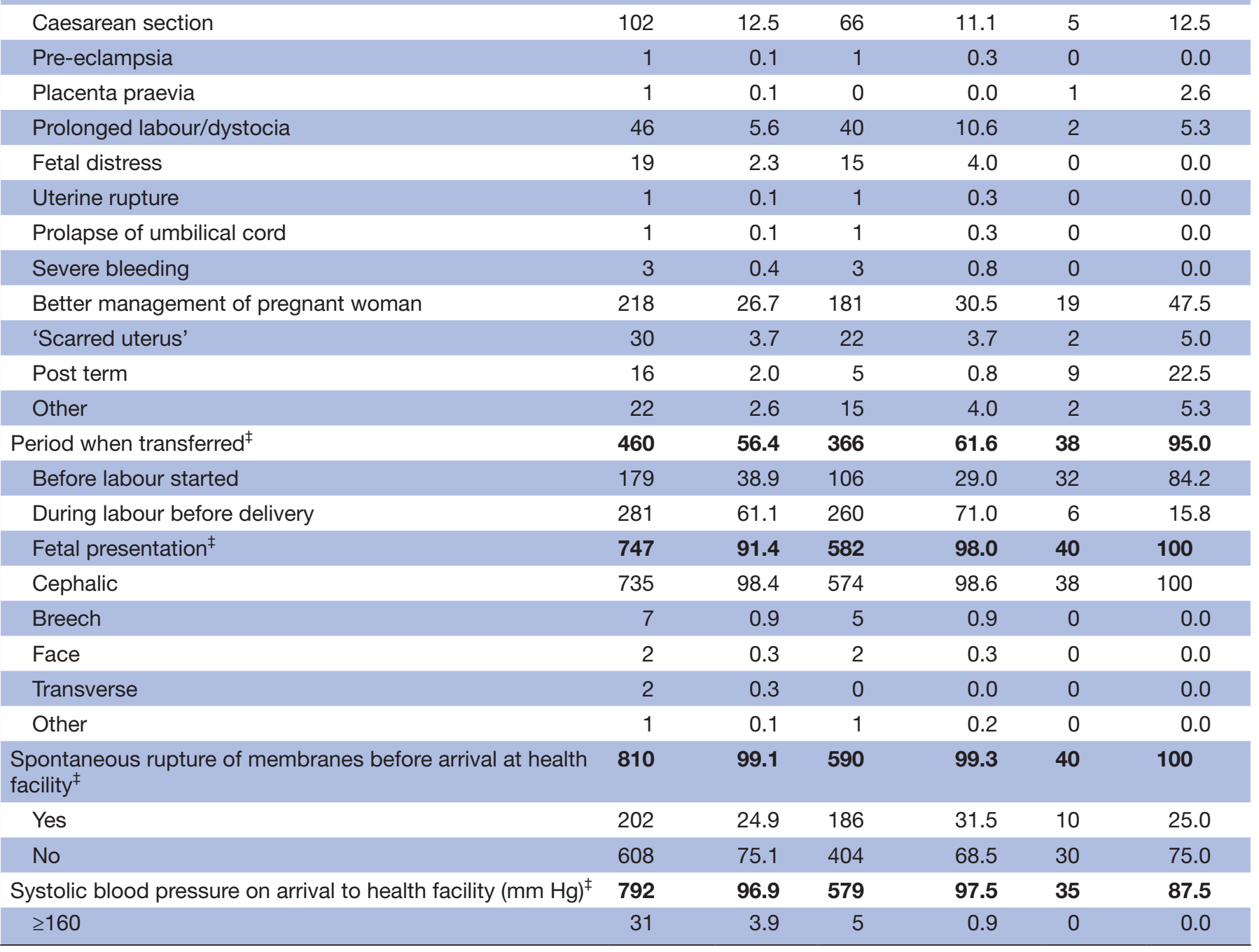

Continued spontaneous labour* induced labour*

All participants

$\begin{array}{llllll}\mathbf{n} & \% & \mathbf{n} & \% & \mathbf{n} & \%\end{array}$

81499.

163

651

815

460

355

460

60

1

39

13

1

7

339

460

20.0

592

99.7

22.0

$78.0 \quad 31$

$99.7 \quad 40$

77.5

$99.8 \quad 592$

$62.2 \quad 34$

85.0

$43.6 \quad 224$

37.8

15.0

$56.4 \quad 594$

100

$4.7 \quad 2$

0.5

$0.1 \quad 1$

0.2

6.1

$1.9 \quad 0$

0.0

$1.6 \quad 11$

0.2

1.0

48.0

0.0

$\begin{array}{rr}0.9 & 6\end{array}$

56.4

402

63.6

35

87.5

100

Participants with Participants with 
Table 3 Continued

\section{Variable}

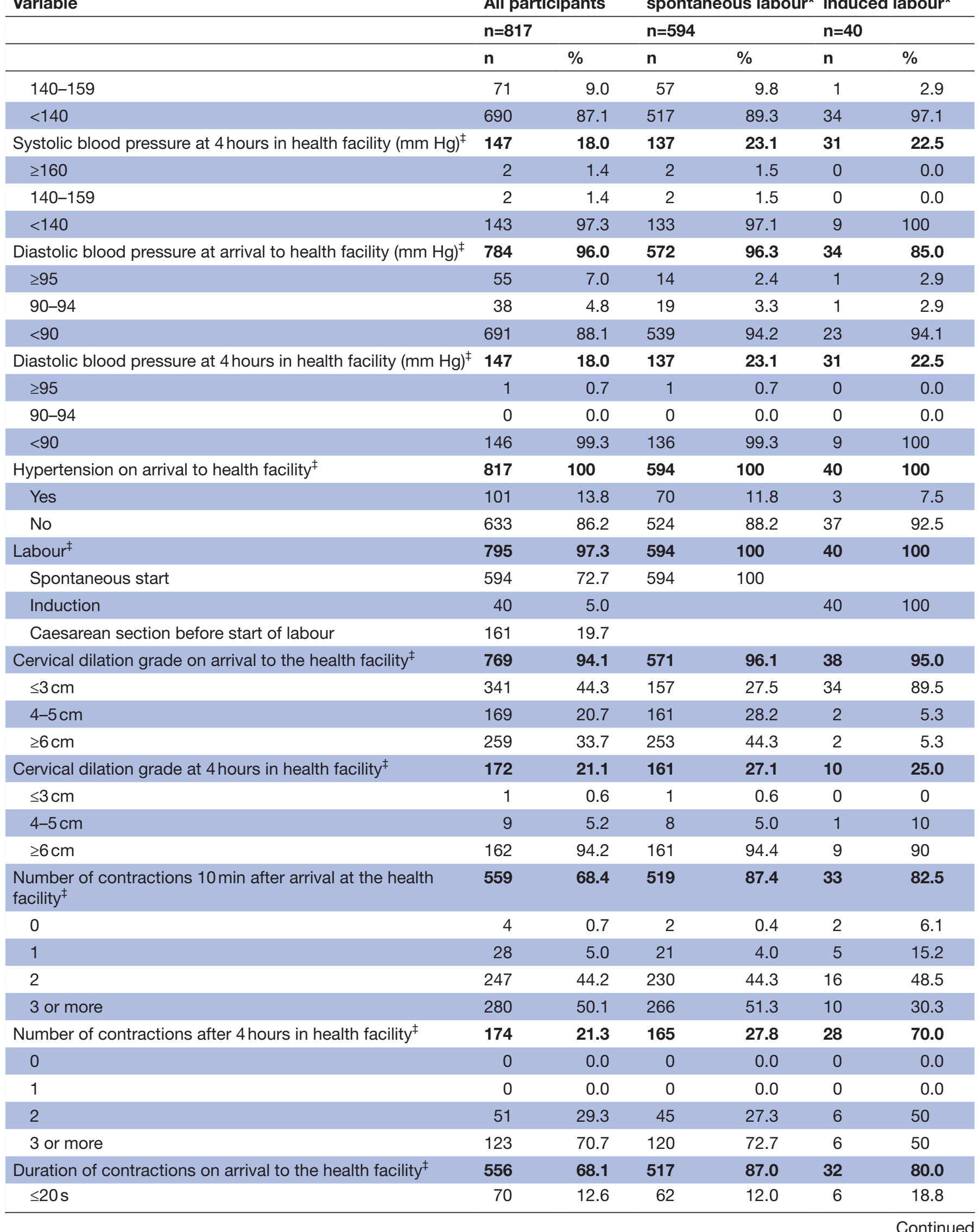


Table 3 Continued

Variable

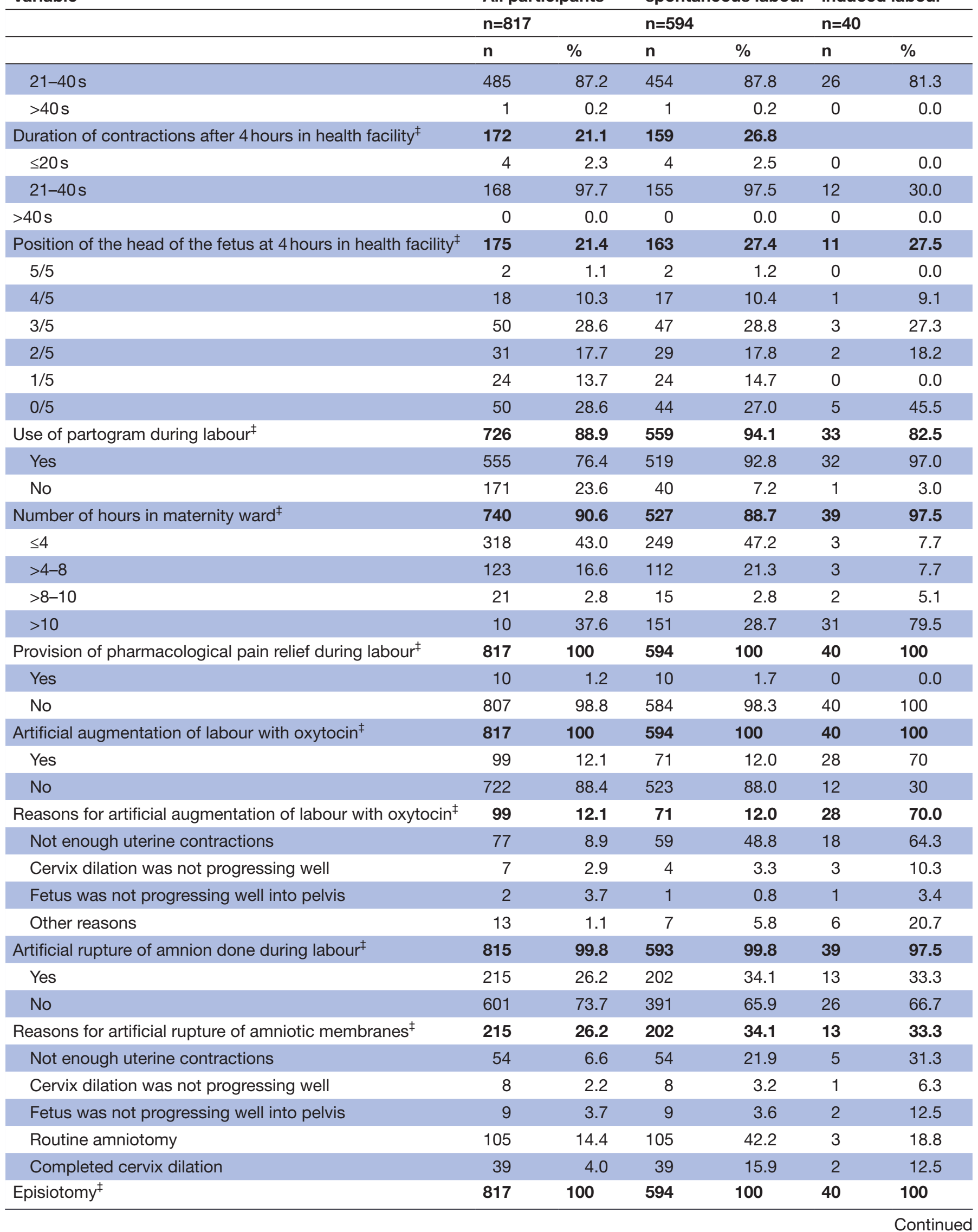
All participants $\begin{array}{ll}\text { Participants with } & \text { Participants with } \\ \text { spontaneous labour* induced labour* }\end{array}$ 
Table 3 Continued

Variable

All participants

Participants with Participants with

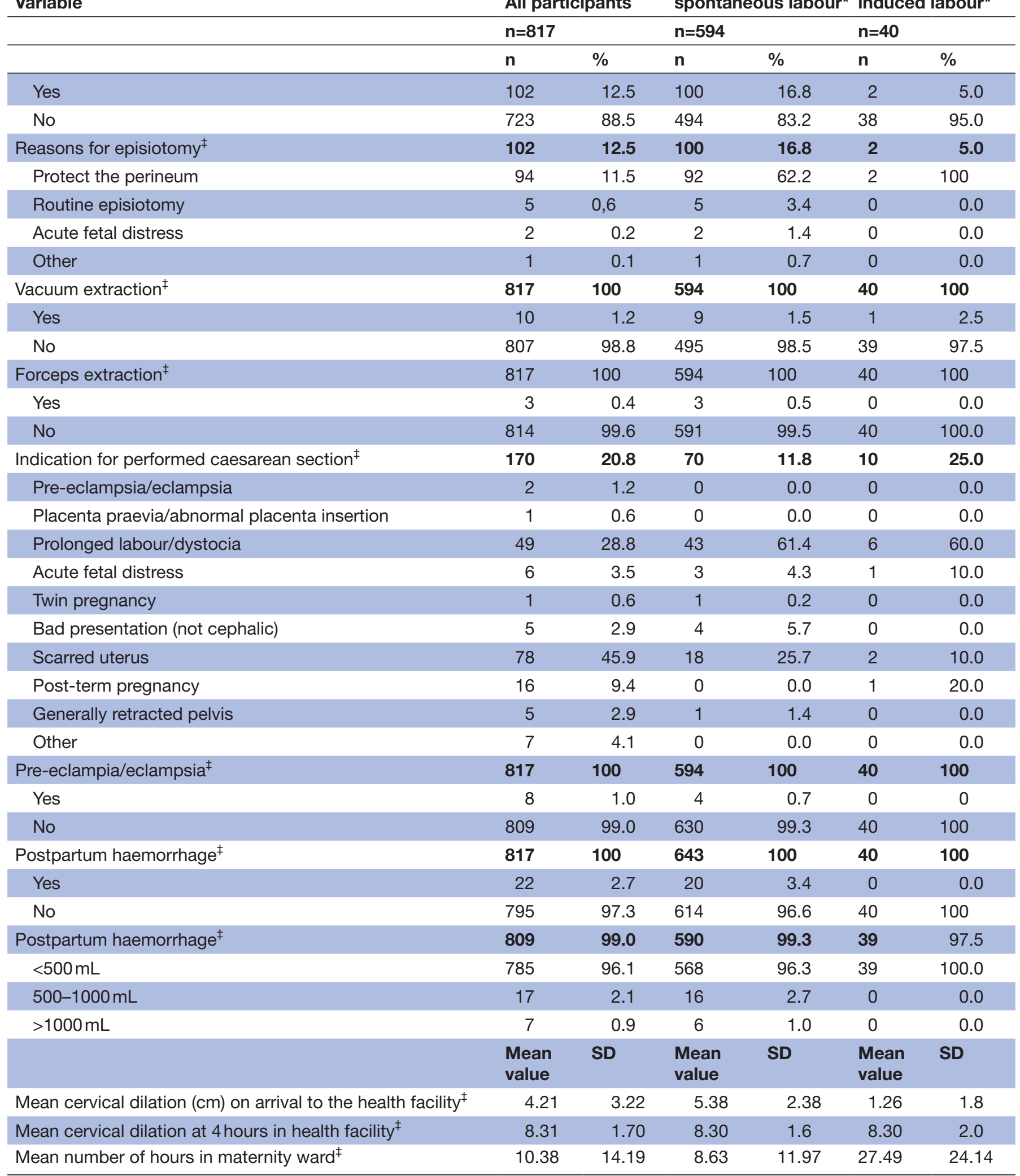

*Women with spontaneous start of labour or with induced labour excluding those with elective caesarean section (self-reported data). †Self-reported data.

¥Medical records data. 
Table 4 Background factors and characteristics of labour in relation to level of healthcare. Test of difference between groups using Pearson's $\chi^{2}$ test and Holm-Bonferroni method ( $p$ value)

\begin{tabular}{|c|c|c|c|c|c|c|c|c|}
\hline \multirow[t]{2}{*}{ Variable } & \multicolumn{2}{|c|}{ Health centre } & \multicolumn{2}{|c|}{ District hospital } & \multicolumn{2}{|c|}{$\begin{array}{l}\text { Referral/private } \\
\text { hospital }\end{array}$} & \multirow[t]{2}{*}{$\begin{array}{l}\chi^{2} \\
\text { p value }\end{array}$} & \multirow[t]{2}{*}{$\begin{array}{l}\text { Holm- } \\
\text { Bonferroni } \\
\text { p value }\end{array}$} \\
\hline & $\mathbf{n}$ & $\%$ & $\mathbf{n}$ & $\%$ & $\mathbf{n}$ & $\%$ & & \\
\hline \multicolumn{9}{|l|}{ Maternal age (years) } \\
\hline$<25$ & 62 & 40.5 & 105 & 25.1 & 70 & 28.7 & & \\
\hline $25-34$ & 70 & 45.8 & 252 & 60.1 & 149 & 61.1 & & \\
\hline$\geq 35$ & 21 & 13.7 & 62 & 14.8 & 25 & 10.1 & 0.003 & 0.069 \\
\hline \multicolumn{9}{|l|}{ Marital status } \\
\hline Married or cohabiting & 138 & 90.8 & 368 & 87.8 & 225 & 92.6 & & \\
\hline Unmarried/single/widow/separated & 14 & 9.2 & 51 & 12.2 & 18 & 7.4 & 0.135 & 1 \\
\hline \multicolumn{9}{|l|}{ Woman's education } \\
\hline $\begin{array}{l}\text { Completed secondary school and reached } \\
\text { university }\end{array}$ & 11 & 7.2 & 126 & 30.1 & 67 & 27.6 & & \\
\hline Completed primary level & 133 & 86.9 & 280 & 66.8 & 169 & 69.5 & & \\
\hline None & 9 & 5.9 & 13 & 3.1 & 7 & 2.7 & $<0.001$ & $<0.001^{*}$ \\
\hline \multicolumn{9}{|l|}{ ANC attendance } \\
\hline Yes & 153 & 100 & 416 & 99.0 & 243 & 99.6 & & \\
\hline No & 0 & 0.0 & 4 & 1.0 & 1 & 0.4 & 0.386 & 1 \\
\hline \multicolumn{9}{|l|}{ Woman's employment } \\
\hline Yes & 143 & 93.5 & 357 & 28.2 & 191 & 82.0 & & \\
\hline No & 10 & 6.5 & 57 & 71.8 & 42 & 18.0 & 0.006 & 0.132 \\
\hline \multicolumn{9}{|l|}{ Health insurance } \\
\hline Yes & 153 & 100.0 & 408 & 97.6 & 241 & 98.8 & & \\
\hline No & 0 & 0.0 & 10 & 2.4 & 3 & 1.2 & 0.182 & 1 \\
\hline \multicolumn{9}{|l|}{ Woman's height (m) } \\
\hline$<1.50$ & 2 & 3.9 & 19 & 9.6 & 2 & 1.6 & & \\
\hline$\geq 1.50$ & 49 & 96.1 & 178 & 90.4 & 125 & 98.4 & 0.010 & 0.200 \\
\hline \multicolumn{9}{|l|}{ Woman's weight before pregnancy $(\mathrm{kg})$} \\
\hline$<50$ & 15 & 10.1 & 65 & 16.0 & 26 & 10.9 & & \\
\hline$\geq 50$ & 133 & 89.9 & 341 & 84.0 & 213 & 89.1 & 0.080 & 1 \\
\hline \multicolumn{9}{|l|}{ Body mass index (BMl; $\mathrm{kg} / \mathrm{m}^{2}$ ) } \\
\hline$<18.5$ & 1 & 2.0 & 11 & 5.8 & 6 & 4.8 & & \\
\hline $18.5-24.9$ & 39 & 76.5 & 121 & 63.4 & 80 & 64.0 & & \\
\hline $25-29.9$ & 8 & 15.7 & 45 & 23.6 & 20 & 16.0 & & \\
\hline$\geq 30$ & 3 & 5.9 & 14 & 7.3 & 14 & 15.2 & 0.098 & 1 \\
\hline \multicolumn{9}{|l|}{ Weight gained during pregnancy $(\mathrm{kg})$} \\
\hline 0 or weight decrease & 9 & 6.5 & 18 & 4.6 & 16 & 7.0 & & \\
\hline $1-10$ & 106 & 76.3 & 305 & 77.2 & 149 & 64.8 & & \\
\hline $10-20$ & 23 & 16.5 & 67 & 17.0 & 62 & 27.0 & & \\
\hline$>20$ & 1 & 0.7 & 5 & 1.3 & 5 & 1.3 & 0.035 & 0.630 \\
\hline \multicolumn{9}{|l|}{ Number of miscarriages } \\
\hline 0 & 136 & 88.9 & 376 & 89.5 & 220 & 90.2 & & \\
\hline 1 & 13 & 8.5 & 36 & 8.6 & 23 & 9.4 & & \\
\hline 2 & 3 & 2.0 & 7 & 1.7 & 0 & 0.0 & & \\
\hline$>2$ & 1 & 0.7 & 1 & 0.2 & 1 & 0.4 & 0.538 & 1 \\
\hline
\end{tabular}


Table 4 Continued

\begin{tabular}{|c|c|c|c|c|c|c|c|c|}
\hline \multirow[t]{2}{*}{ Variable } & \multicolumn{2}{|c|}{ Health centre } & \multicolumn{2}{|c|}{ District hospital } & \multicolumn{2}{|c|}{$\begin{array}{l}\text { Referral/private } \\
\text { hospital }\end{array}$} & \multirow[t]{2}{*}{$\begin{array}{l}\chi^{2} \\
\mathrm{p} \text { value }\end{array}$} & \multirow[t]{2}{*}{$\begin{array}{l}\text { Bonferroni } \\
\text { p value }\end{array}$} \\
\hline & $\mathbf{n}$ & $\%$ & $\mathbf{n}$ & $\%$ & $\mathbf{n}$ & $\%$ & & \\
\hline \multicolumn{9}{|l|}{ Number of births (including the index child) } \\
\hline Primiparity & 54 & 35.3 & 177 & 42.1 & 103 & 42.4 & & \\
\hline Multiparity & 99 & 64.7 & 243 & 57.9 & 140 & 57.6 & 0.290 & 1 \\
\hline$\geq 1$ & 19 & 12.4 & 33 & 7.9 & 10 & 4.1 & 0.009 & 0.189 \\
\hline \multicolumn{9}{|l|}{ Hypertension during pregnancy } \\
\hline No & 148 & 96.7 & 391 & 93.1 & 235 & 96.3 & & \\
\hline Yes & 5 & 3.3 & 29 & 6.9 & 9 & 3.7 & 0.095 & 1 \\
\hline \multicolumn{9}{|l|}{ Transfer from other health facility } \\
\hline Yes & 6 & 3.9 & 287 & 68.3 & 167 & 68.4 & & \\
\hline No & 147 & 96.1 & 133 & 31.7 & 77 & 31.6 & $<0.001$ & $<0.001^{*}$ \\
\hline \multicolumn{9}{|l|}{ Labour } \\
\hline Spontaneous labour and vaginal delivery & 148 & 96.7 & 221 & 52.6 & 164 & 67.2 & & \\
\hline $\begin{array}{l}\text { Spontaneous labour and delivery by } \\
\text { caesarean section }\end{array}$ & 0 & 0.0 & 44 & 10.5 & 17 & 7.0 & & \\
\hline Induction of labour & 2 & 1.3 & 27 & 6.4 & 11 & 4.5 & & \\
\hline Caesarean section before labour & 0 & 0.0 & 122 & 29.0 & 39 & 16.0 & $<0.001$ & $<0.001^{*}$ \\
\hline
\end{tabular}

Cervical dilation grade on arrival at health facility

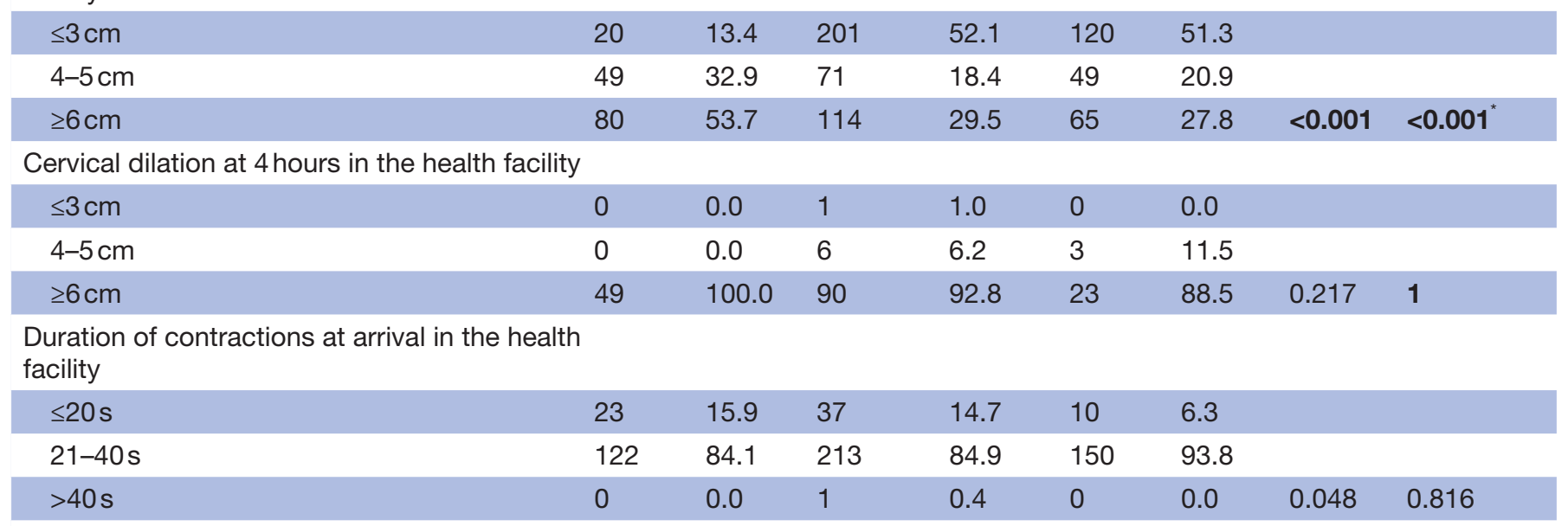

Duration of contractions at 4 hours in the health facility

\begin{tabular}{|c|c|c|c|c|c|c|c|c|}
\hline$\leq 20 \mathrm{~s}$ & 2 & 4.0 & 1 & 1.0 & 1 & 3.8 & & \\
\hline $21-40 \mathrm{~s}$ & 48 & 96.0 & 95 & 99.0 & 25 & 96.2 & & \\
\hline$>40 s$ & 0 & 0.0 & 0 & 0.0 & 0 & 0.0 & 0.454 & 1 \\
\hline Yes & 144 & 99.3 & 248 & 32.6 & 163 & 76.5 & & \\
\hline No & 1 & 0.7 & 120 & & 50 & 23.5 & $<0.001$ & $<0.001$ \\
\hline
\end{tabular}


Table 4 Continued

\begin{tabular}{|c|c|c|c|c|c|c|c|c|}
\hline \multirow[t]{2}{*}{ Variable } & \multicolumn{2}{|c|}{ Health centre } & \multicolumn{2}{|c|}{ District hospital } & \multicolumn{2}{|c|}{$\begin{array}{l}\text { Referral/private } \\
\text { hospital }\end{array}$} & \multirow[t]{2}{*}{$\begin{array}{l}\chi^{2} \\
\text { p value }\end{array}$} & \multirow[t]{2}{*}{$\begin{array}{l}\text { Holm- } \\
\text { Bonferroni } \\
\text { p value }\end{array}$} \\
\hline & $\mathbf{n}$ & $\%$ & $\mathbf{n}$ & $\%$ & $\mathbf{n}$ & $\%$ & & \\
\hline Pharmacological pain relief during labour & & & & 1.4 & & & & \\
\hline Yes & 2 & 1.3 & 6 & 98.6 & 2 & 0.8 & & \\
\hline No & 151 & 98.7 & 414 & & 242 & 99.2 & 0.785 & 1 \\
\hline Caesarean section done during labour & & & & 11.9 & & & & \\
\hline Yes & 0 & 0.0 & 50 & 88.1 & 21 & 8.6 & & \\
\hline No & 153 & 100. & 370 & & 223 & 91.4 & $<0.001$ & $<0.001^{*}$ \\
\hline Health provider assisting the delivery & & & & 6.0 & & & & \\
\hline Nurse & 125 & 84.5 & 25 & 41.0 & 3 & 1.2 & & \\
\hline Midwife & 23 & 15.5 & 170 & 53.0 & 130 & 53.3 & & \\
\hline Doctor & 0 & 0.0 & 220 & & 111 & 45.5 & $<0.001$ & $0.002^{\star}$ \\
\hline \multicolumn{9}{|l|}{ Pre-eclampsia/eclampsia } \\
\hline Yes & 2 & 1.3 & 4 & 1.0 & 2 & 0.8 & & \\
\hline No & 151 & 98.7 & 416 & 99.0 & 242 & 99.2 & 0.888 & 1 \\
\hline \multicolumn{9}{|l|}{ Caesarean section due to prolonged labour } \\
\hline Yes & 0 & 0.0 & 19 & 4.5 & 24 & 9.8 & & \\
\hline No & 153 & 100 & 401 & 95.5 & 220 & 90.2 & $<0.001$ & $<0.001^{*}$ \\
\hline \multicolumn{9}{|l|}{ Postpartum haemorrhage } \\
\hline Yes & 6 & 3.9 & 13 & 3.1 & 3 & 1.2 & & \\
\hline No & 147 & 96.1 & 407 & 96.9 & 241 & 98.8 & 0.209 & 1 \\
\hline \multicolumn{9}{|l|}{ Self-rated health before pregnancy $\dagger$} \\
\hline Good & 138 & 90.2 & 375 & 89.5 & 234 & 95.9 & & \\
\hline Poor & 15 & 9.8 & 44 & 10.5 & 10 & 4.1 & 0.014 & 0.266 \\
\hline \multicolumn{9}{|l|}{ Self-rated health during pregnancy $†$} \\
\hline Good & 101 & 66.0 & 284 & 67.8 & 177 & 72.5 & & \\
\hline Poor & 52 & 34.0 & 135 & 32.2 & 67 & 27.5 & 0.309 & 1 \\
\hline \multicolumn{9}{|l|}{ Self-rated health postpartum $\dagger$} \\
\hline Good & 136 & 88.9 & 366 & 87.1 & 201 & 82.4 & & \\
\hline Poor & 17 & 11.1 & 54 & 12.9 & 43 & 17.6 & 0.123 & 1 \\
\hline
\end{tabular}

${ }^{*}$ Statistical significant $\mathrm{p}$ value after correction with Holm-Bonferroni method.

†Poor-SRH (poor self-rated health status) includes very poor and poor health status categories and good-SRH (good self-rated health status) includes very good and good health status categories.

ANC, antenatal care.

Pregnant women who arrived at a health facility with a cervical dilation grade $\leq 3 \mathrm{~cm}$, and who did not receive oxytocin during labour, spent more hours in a maternity ward compared with those who arrived with a cervical dilation grade $\leq 3 \mathrm{~cm}$ and who received oxytocin during labour (median value 14.17 hours; IQR: 5.42-19.58; p<0.001) (figure 3). Pregnant women who arrived at a health facility with a cervical dilation grade between 4 and $5 \mathrm{~cm}$ and who did not receive oxytocin during labour spent more hours in a maternity ward compared with those who arrived with a cervical dilation grade between 4 and $5 \mathrm{~cm}$ and received oxytocin during labour (median value 5.13 hours; IQR: 3.16-8.31; $\mathrm{p}=0.007)$. Those who arrived at a health facility with a cervical dilation grade $\geq 6 \mathrm{~cm}$ and did not receive oxytocin during labour spent more hours in a maternity ward compared with those who arrived with a cervical dilation grade $\geq 6 \mathrm{~cm}$ and received oxytocin during labour (median value 1.45 hours; IQR: 0.50-3.67; $\mathrm{p}<0.001$ ).

\section{Prevalence of pregnancy-related complications}

The prevalence of hypertension on arrival to the health facility was $13.8 \%$. The prevalence of eclampsia/pre-eclampsia, PPH and CS due to prolonged/dystocia labour was $1 \%, 2.7 \%$, and $5.4 \%$ of all pregnant women, respectively. Prolonged/dystocia labour comprised $28.8 \%$ of all indications for CS. 


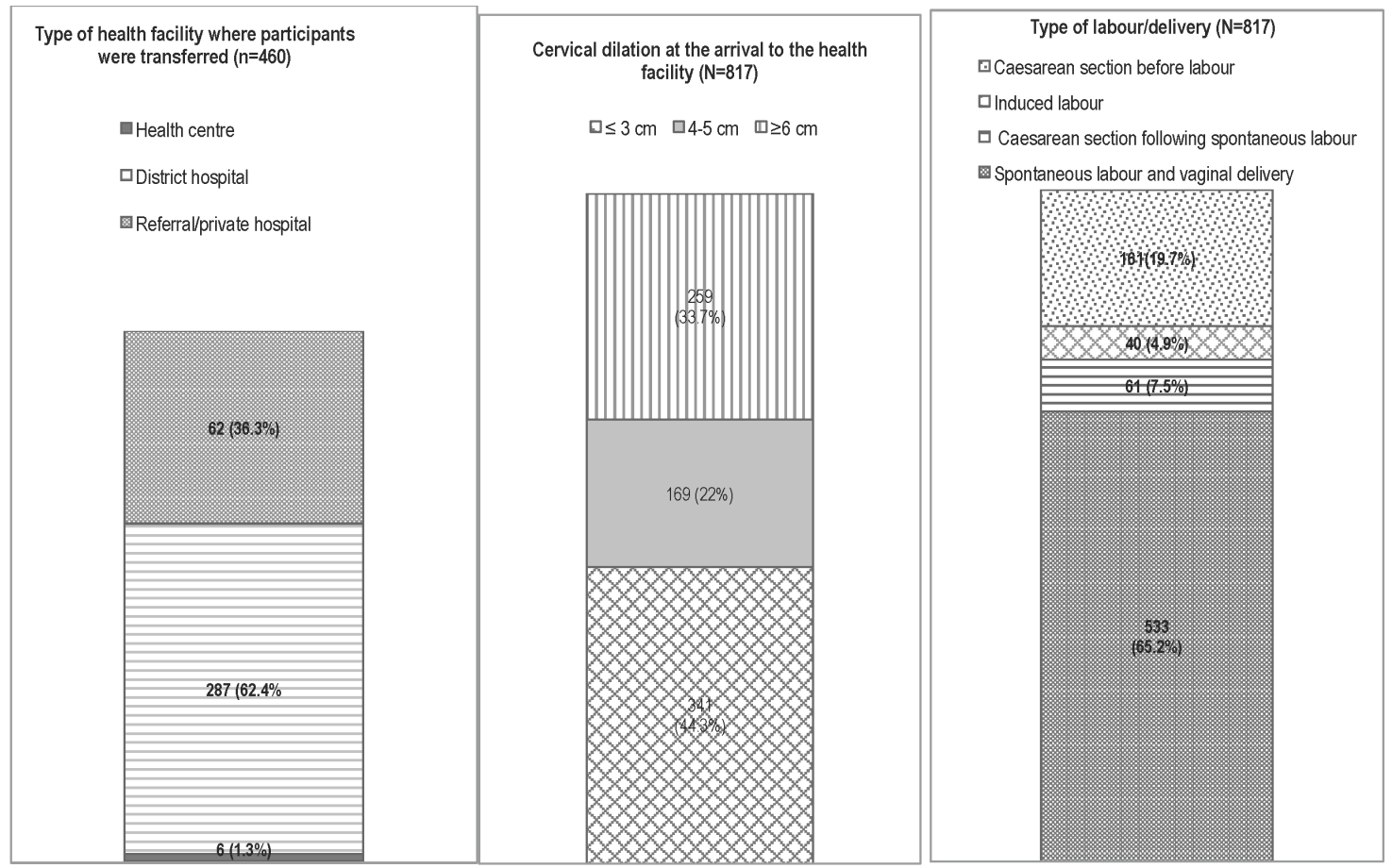

Figure 1 Type of health facility where participants were transferred, cervical dilation grade on arrival at health facility and description of delivery.

\section{Factors associated with caesarean section due to prolonged labour/dystocia}

In the bivariable analysis, the following were statistically significant factors associated with CS due to prolonged labour/dystocia: poor households with a monthly income of less than 36000 RWF (ie, approximately \$US45), residence far from a health facility (distance from home to a health facility $>1 \mathrm{~km}$ ) and cervical dilation grade $<6 \mathrm{~cm}$ on arrival to a health facility. In the multivariable analysis, the same background factors and nulliparity were significantly associated with CS due to prolonged labour/ dystocia (table 5).

\section{DISCUSSION}

In this study, we found that the prevalence of health facility-based pre-eclampsia/eclampsia and $\mathrm{PPH}$ were very low ( $1 \%$ and $2.7 \%$, respectively). CS was the main reason for transfer of women from health centres to district hospitals, and dystocia/prolonged labour was the main indication for CS. Furthermore, risk factors for having a CS due to prolonged labour included living in a poor household, nulliparity and residence far from a health facility.

The estimated prevalence of self-reported pregnancy-related health problems during pregnancy-that is, anaemia, severe vaginal bleeding, hypertension, and

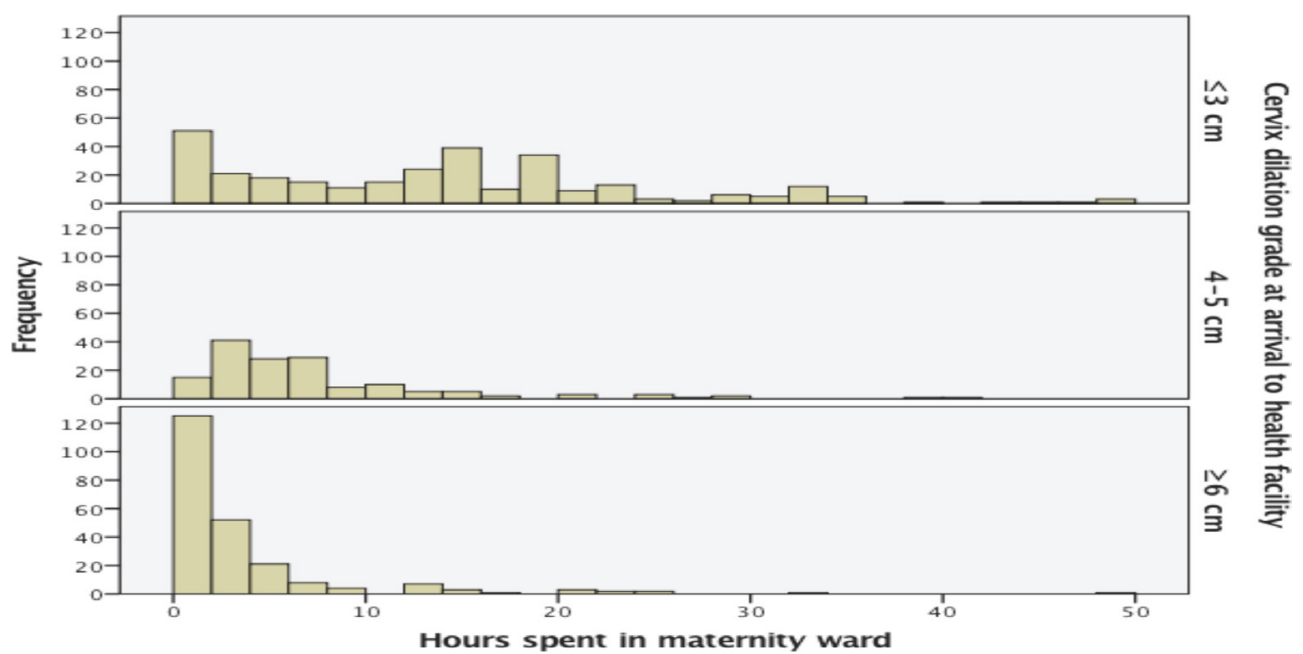

Figure 2 Frequency of participants in relation to the number of hours in the maternity ward until delivery and in relation to category of grade of cervical dilation at arrival to health facility. 


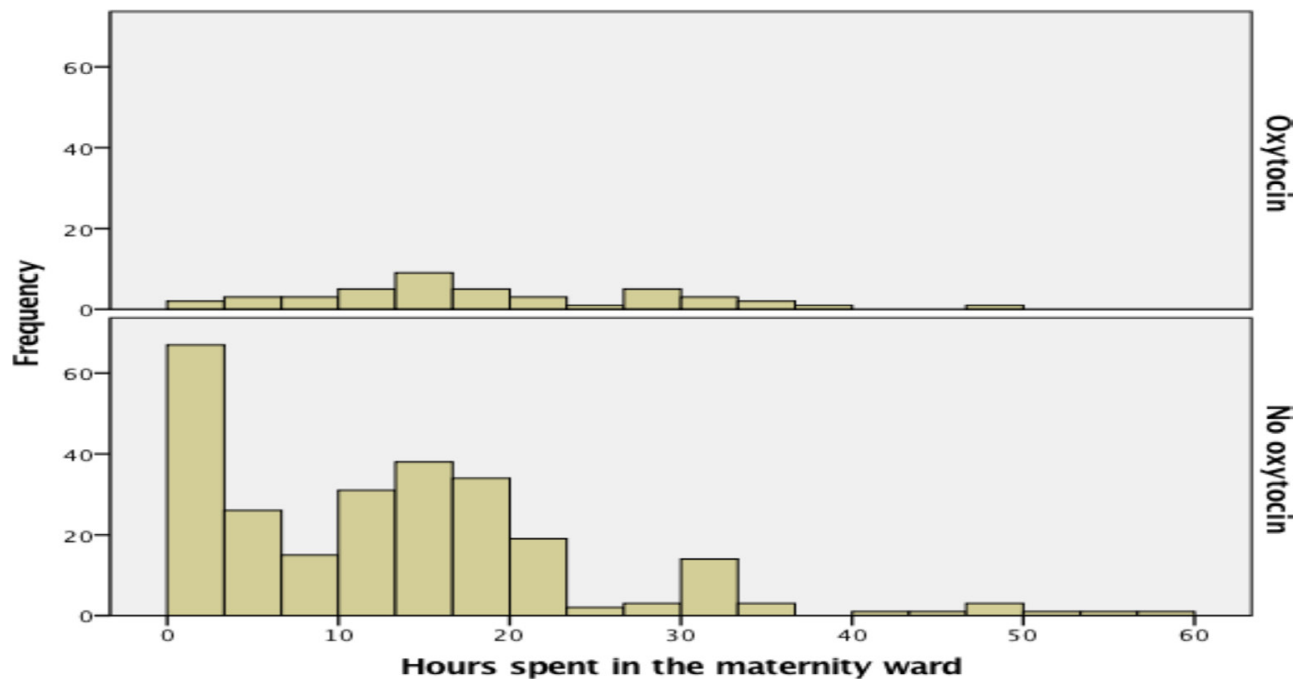

Figure 3 Frequency of participants in relation to the number of hours in the maternity ward until delivery and in relation to use $(n=49)$ or non-use of oxytocin $(n=292)$ for participants with cervical dilation grade of $\leq 3 \mathrm{~cm}$ on arrival to the health facility.

diabetes mellitus-were comparable with results from other studies. Previously, the prevalence for self-reported anaemia for women of reproductive age in Rwanda has been found to be similar to that in our study. ${ }^{16}$ In addition, self-reported postpartum anaemia investigated in China is comparable with our findings ${ }^{26}$; sub-Saharan African prevalence of gestational diabetes mellitus is also similar to the range found in our study. ${ }^{927}$ The estimated prevalence of pregnancy-related complications pre-eclampsia/ eclampsia and PPH was very low compared with the prevalence in other countries in Africa. ${ }^{7828}$ For example, in other low and middle income sub-Saharan African countries, the prevalence of pre-eclampsia is estimated to be three times higher than our result. ${ }^{8}$ However, one study reported the prevalence of pre-eclampsia/eclampsia in neighbouring countries of Rwanda (Democratic Republic of Congo, Kenya and Uganda) as being similar to the results of our study. ${ }^{10}$ In referral hospitals in Rwanda and Uganda, PPH is 3-10 times more common than estimated in our study. ${ }^{6728}$ Possible explanations for these differences may be misclassifications by healthcare providers. For example, pre-eclampsia may have been incorrectly classified as other hypertensive disorder during pregnancy or not been classified. Another explanation for these differences is that we only included survivors of pregnancy-related complications so we underestimated the true prevalence of the condition because a number of women actually died from these complications. In a tertiary care hospital in Rwanda, postpartum haemorrhage and pre-eclampsia/eclampsia represented a case fatality rate of $22 \%$ and $16 \%$, respectively. ${ }^{7}$ Health providers may have under-reported PPH cases after having managed to stabilise the woman because they misevaluated the quantity of blood loss. Another explanation may be that the healthcare providers were not able to adequately evaluate total blood loss because the woman had been transferred from another health facility. Moreover, some physicians may not want to report postpartum haemorrhage to avoid audit problems because the Ministry of Health has introduced maternal death audits in health centres and district hospitals for such cases. ${ }^{29}$

The majority of women referred were transferred from health centres to district hospitals. Most of the women who gave birth in district and referral hospitals were transferred from a facility providing a lower level of healthcare. These results are in the line with the pyramidal composition of the Rwandan health system in which a large number of cases are managed at lower levels of healthcare, and only complicated cases are referred to the next level of healthcare. ${ }^{23}$ In about one-third of cases, a partogram was not used to monitor labour in pregnant women delivering in district and referral hospitals. This result is low compared with WHO recommendations of using partograms for all women in monitoring labour, although it is comparable with results obtained in Uganda. ${ }^{30} 31$

CS was the main reason for being transferred, and previous studies show that in sub-Saharan Africa transfer of pregnant women in labour is always associated with a risk of delay due to lack of transportation and bad roads, a situation that increases the risk of additional complications such as maternal fistula or even fetal death. ${ }^{32} 33$ Upgrading the capacity of health centres in the management of pregnant women with special focus on the management of prolonged labour/dystocia and performing CS may decrease the number of maternal transfers, prevent risks related to prolonged labour and allow district hospitals to receive fewer cases. This would enable the district hospitals to spend more time on other pregnancy-related complications. Since 2012, clinical officers in Rwanda have been trained, and two cohorts of clinical officers have been graduated but are not yet engaged in the Rwandan health system. ${ }^{34}$ The use of these newly trained clinical officers in Rwandan health centres, a strategy used in other middle-income and low-income sub-Saharan countries, may be of significance as it has been shown that there are few differences in clinical outcomes after CS performed by clinical 
Open Access

Table 5 Bivariable and multivariable logistic regression analyses with calculation of crude ORs and adjusted ORs and their 95\% Cls for CS due to prolonged labour/dystocia in relation to specified background variables

\begin{tabular}{|c|c|c|c|c|c|c|c|c|}
\hline \multirow[t]{4}{*}{ Variable } & \multicolumn{8}{|c|}{ Caesarean section due to prolonged labour/dystocia } \\
\hline & \multicolumn{6}{|c|}{ Bivariable analysis } & \multicolumn{2}{|c|}{ Multivariable analysis } \\
\hline & \multicolumn{2}{|c|}{ Yes } & \multicolumn{4}{|l|}{ No } & \multirow[b]{2}{*}{ Adjusted OR } & \multirow[b]{2}{*}{$95 \% \mathrm{Cl}$} \\
\hline & $\mathbf{N}$ & $\%$ & $\mathbf{N}$ & $\%$ & Crude OR & $95 \% \mathrm{Cl}$ & & \\
\hline \multicolumn{9}{|l|}{ Maternal age (years) } \\
\hline$<25$ & 13 & 5.5 & 224 & 94.5 & 1 & & 1 & \\
\hline $25-34$ & 28 & 5.9 & 443 & 94.1 & 0.91 & $0.46-1.80$ & 0.67 & $0.30-1.48$ \\
\hline$\geq 35$ & 2 & 1.9 & 106 & 98.1 & 0.29 & $0.70-1.27$ & 0.40 & $0.09-1.80$ \\
\hline \multicolumn{9}{|l|}{ Marital status } \\
\hline Married or cohabiting & 41 & 5.6 & 690 & 94.4 & 1 & & & \\
\hline $\begin{array}{l}\text { Unmarried or single or widow or } \\
\text { separated }\end{array}$ & 2 & 2.4 & 81 & 97.6 & 0.41 & $0.09-1.75$ & & \\
\hline \multicolumn{9}{|l|}{ Women's education } \\
\hline $\begin{array}{l}\text { Completed secondary level or } \\
\text { reached university level }\end{array}$ & 13 & 6.4 & 191 & 93.6 & 1 & & & \\
\hline Completed primary level & 29 & 5.0 & 553 & 95.0 & 0.77 & $0.92--1.51$ & & \\
\hline Never attended school & 1 & 3.4 & 28 & 96.6 & 0.52 & $0.06--4.16$ & & \\
\hline \multicolumn{9}{|l|}{ Woman's employment } \\
\hline Employed & 37 & 5.4 & 654 & 94.6 & 1 & & & \\
\hline Not employed & 6 & 5.5 & 102 & 94.5 & 1.03 & $0.42--2.50$ & & \\
\hline \multicolumn{9}{|l|}{ Number of births } \\
\hline Multiparity & 12 & 2.7 & 434 & 97.3 & 1 & & 1 & \\
\hline Primiparity & 1 & 2.9 & 34 & 97.1 & 1.03 & $0.13-8.18$ & 3.79 & $1.79-8.01$ \\
\hline
\end{tabular}

Number of previous children

delivered at home

\begin{tabular}{|c|c|c|c|c|c|c|c|c|}
\hline None & 40 & 5.3 & 715 & 94.7 & 1 & & & \\
\hline 1 or more & 3 & 4.8 & 59 & 95.2 & 0.90 & $0.27-3.02$ & & \\
\hline \multicolumn{9}{|c|}{ History of miscarriages } \\
\hline No & 37 & 5.6 & 621 & 94.4 & & & & \\
\hline Yes & 5 & 6.6 & 71 & 93.4 & 1.18 & $0.45-3.10$ & & \\
\hline \multicolumn{9}{|l|}{ HIV status } \\
\hline Negative & 42 & 5.5 & 723 & 94.5 & 1 & & & \\
\hline Positive & 1 & 1.9 & 51 & 98.1 & 2.96 & $0.40-21.96$ & & \\
\hline \multicolumn{9}{|l|}{ Health insurance } \\
\hline Yes & 42 & 5.2 & 760 & 94.8 & 1 & & & \\
\hline No & 1 & 7.7 & 12 & 92.3 & 1.50 & $0.19-11.87$ & & \\
\hline \multicolumn{9}{|c|}{ Household monthly income } \\
\hline$\geq 36000$ RWF & 11 & 10.9 & 90 & 89.1 & 1 & & 1 & \\
\hline$<36000$ RWF & 32 & 4.8 & 641 & 95.2 & 2.44 & $1.19-5.02$ & 4.86 & $2.08-11.35$ \\
\hline \multicolumn{9}{|c|}{ Distance to the health facility } \\
\hline$\leq 1 \mathrm{~km}$ & 32 & 7.2 & 413 & 92.8 & 1 & & 1 & \\
\hline$>1 \mathrm{~km}$ & 11 & 3.0 & 358 & 97.0 & 2.55 & $1.25-5.07$ & 3.30 & $1.53-7.11$ \\
\hline \multicolumn{9}{|c|}{ Antenatal care visit } \\
\hline Yes & 41 & 5.3 & 737 & 94.7 & 1 & & & \\
\hline No & 1 & 3.3 & 29 & 96.7 & 1.61 & $0.21-12.13$ & & \\
\hline Anaemia during & & & & & & & & \\
\hline
\end{tabular}




\begin{tabular}{|c|c|c|c|c|c|c|c|c|}
\hline \multirow[t]{4}{*}{ Variable } & \multicolumn{8}{|c|}{ Caesarean section due to prolonged labour/dystocia } \\
\hline & \multicolumn{6}{|c|}{ Bivariable analysis } & \multicolumn{2}{|c|}{ Multivariable analysis } \\
\hline & \multicolumn{2}{|c|}{ Yes } & \multicolumn{4}{|l|}{ No } & \multirow[b]{2}{*}{ Adjusted OR } & \multirow[b]{2}{*}{$95 \% \mathrm{Cl}$} \\
\hline & $\mathbf{N}$ & $\%$ & $\mathbf{N}$ & $\%$ & Crude OR & $95 \% \mathrm{Cl}$ & & \\
\hline No & 39 & 5.6 & 656 & 94.4 & 1 & & & \\
\hline Yes & 4 & 3.3 & 118 & 96.7 & 0.57 & $0.20-1.62$ & & \\
\hline \multicolumn{9}{|l|}{ Bad smell during pregnancy } \\
\hline No & 42 & 5.8 & 683 & 94.2 & 1 & & & \\
\hline Yes & 1 & 1.1 & 91 & 98.9 & 0.17 & $0.02-1.31$ & & \\
\hline \multicolumn{9}{|l|}{ Transfer from another health facility } \\
\hline No & 14 & 3.9 & 343 & 96.1 & 1 & & & \\
\hline Yes & 29 & 6.3 & 431 & 93.7 & 1.64 & $0.85-3.16$ & & \\
\hline \multicolumn{9}{|l|}{ When transferred } \\
\hline Before start of labour & 7 & 3.9 & 172 & 96.1 & 1 & & & \\
\hline During labour before delivery & 22 & 7.8 & 259 & 92.2 & 2.08 & $0.87-4.99$ & & \\
\hline \multicolumn{9}{|l|}{$\begin{array}{l}\text { Cervical dilation grade on arrival to } \\
\text { health facility }\end{array}$} \\
\hline$\leq 3 \mathrm{~cm}$ & 28 & 8.2 & 313 & 91.8 & 4.54 & $1.73-11.93$ & 6.17 & $2.20-17.28$ \\
\hline $4-5 \mathrm{~cm}$ & 10 & 5.9 & 159 & 94.1 & 3.19 & $1.07-9.51$ & 4.03 & $1.27-12.71$ \\
\hline$\geq 6 \mathrm{~cm}$ & 5 & 1.9 & 254 & 98.1 & 1 & & 1 & \\
\hline \multicolumn{9}{|l|}{ Woman's weight (kg) } \\
\hline$<50$ & 5 & 4.7 & 101 & 95.3 & 1.11 & $0.42-2.91$ & & \\
\hline$\geq 50$ & 36 & 5.2 & 651 & 94.8 & 1 & & & \\
\hline
\end{tabular}

Self-rated health before pregnancy*

\begin{tabular}{lllllllll} 
Good & 42 & 5.6 & 705 & 94.4 & 1 & & & \\
$\quad$ Poor & 1 & 1.4 & 68 & 98.6 & 0.24 & $0-03-.82$ & & \\
$\begin{array}{l}\text { Self-rated health during } \\
\text { pregnancy* }\end{array}$ & & & & & & & & \\
$\quad$ Good & 39 & 6.9 & 523 & 93.1 & 1 & & $\mathbf{1}$ & \\
$\quad$ Poor & 4 & 1.6 & 250 & 98.4 & $\mathbf{0 . 2 1}$ & $\mathbf{0 . 0 7 - 0 . 6 0}$ & $\mathbf{0 . 2 2}$ & $\mathbf{0 . 0 7 - 0 . 6 5}$ \\
\hline
\end{tabular}

${ }^{*}$ Poor-SRH (poor self-rated health status includes very poor and poor health status categories and good-SRH (good self- rated health status) includes very good and good health status categories.

officers or physicians. ${ }^{34}{ }^{35}$ In this study, the CS rate was almost two times higher than the national rate and higher than the recommended WHO rate, but the CS rates were in the range of those in Kigali hospitals. ${ }^{70} 36$

Being in a poor household located far from a health facility was a statistically significant factor associated with CS due to prolonged labour/dystocia. This finding is in agreement with previous studies reporting a statistical association between prolonged labour and low socioeconomic level and being a pregnant woman living in a rural area. ${ }^{37}$ Poor roads and long distances to a health facility are risk factors for prolonged labour/dystocia. ${ }^{33}$ Arriving at a health facility with cervical dilation grade of less than $6 \mathrm{~cm}$ and being nulliparous were factors associated with CS due to prolonged labour/dystocia. It has been reported previously that less advanced cervical dilation grade at admission and nulliparity are risk factors for prolonged labour. ${ }^{37} 38$

\section{Methodological considerations}

One strength of this study is that all the women eligible consented to participate. In Rwanda, all health-related studies that are conducted need both ethical approval from the Rwandan National Ethics Committee and authorisation from the Ministry of Health. Commonly, the Ministry of Health is associated with these studies. This may contribute to the high participation rates seen in almost all studies done in Rwanda, since Rwandan people are known to comply with all activities conducted by the government. ${ }^{16}$ 39-41 Female professional interviewers with nursing and midwifery backgrounds, who were not working at the selected health facilities, were 
employed because of their knowledge of the items in the questionnaire and the terminology used in medical records. The strategy was also used to make the women feel comfortable while responding to questions. One limitation is that this study estimated only the health facility prevalence of complications related to pregnancy. There may be under-reporting of the prevalence of complications related to pregnancy as, for example, in the case of maternal deaths occurring in the community. Pregnancy-related complications are mainly managed at the district hospital level. However, these hospitals are mainly staffed with general practitioners who may have high workloads and limited knowledge of pregnancy-related complications. In addition, the hospitals often lack the equipment necessary for management of complicated pregnancies. ${ }^{42}$ This may have led to under-reporting of some cases by misinterpretation. There may have been some over-reporting of cases in relation to the population-based prevalence because of selection bias, since cases with complications are aggregated in hospitals for more advanced healthcare.

\section{CONCLUSIONS}

The health facility-based prevalence of pre-eclampsia/ eclampsia, PPH and CS due to prolonged labour/dystocia was low in this sample from Rwanda. The estimated prevalences in this study were probably underestimated due to the high workload and limited obstetric knowledge of physicians. The majority of pregnant women giving birth at district hospitals were transferred from health centres, and CS was the main reason for transfer. Prolonged labour was the main indication of CS during labour. Almost half of the women who were delivered at district hospitals were assisted by a physician. Upgrading the capacity of Rwandan health centres by using clinical officers may decrease the number of maternal transferrals to facilities with higher level of healthcare, decrease risks of aggravation of pregnancy-related complications during transferral and improve maternal and fetal health.

\section{Author affiliations \\ ${ }^{1}$ Department of Clinical Sciences, Obstetrics and Gynaecology, Umeå University, Umeå, Sweden \\ ${ }^{2}$ University of Rwanda College of Medicine and Health Sciences School of Public Health, Kigali, Rwanda \\ ${ }^{3}$ Department of Public Health and Community Medicine and Public Health, Sahlgrenska Academy, University of Gothenburg, Gothenburg, Sweden \\ ${ }^{4}$ Judith Lumley Centre, La Trobe University, Melbourne, Victoria, Australia}

Acknowledgements Our sincere thanks go to the participating Rwandan women and selected health facilities. We also thank Anni-Maria Pulkki-Brännström, Marie Berg and Anna Dencker for their helpful contribution to this study. We also thank the Swedish International Development Agency for funding, the University of Rwanda for logistic support and Umeå University for its overall support.

Contributors All authors participated in the design of the study and the development of the study tools. All authors contributed to the drafting of the manuscript. JPSS participated in data collection in the field in collaboration with MN and CM. JPSS performed the data analysis under supervision of IM. JPSS wrote the manuscript under supervision of IM and in collaboration with all other authors. All authors read and approved the final version of the manuscript.
Competing interests None declared.

Patient consent This article does not contain personal medical information about an identifiable living individual.

Ethics approval The research protocol and the study questionnaire were approved by the University of Rwanda, College of Medicine and Health Sciences Institutional Review Board

Provenance and peer review Not commissioned; externally peer reviewed.

Data sharing statement The datasets used and analysed during the current study will be available from the corresponding author upon receiving a reasonable request.

Open Access This is an Open Access article distributed in accordance with the Creative Commons Attribution Non Commercial (CC BY-NC 4.0) license, which permits others to distribute, remix, adapt, build upon this work non-commercially, and license their derivative works on different terms, provided the original work is properly cited and the use is non-commercial. See: http://creativecommons.org/ licenses/by-nc/4.0/

(c) Article author(s) (or their employer(s) unless otherwise stated in the text of the article) 2017. All rights reserved. No commercial use is permitted unless otherwise expressly granted.

\section{REFERENCES}

1. WHO. The World Health Report 2005, Make every mother and child count, 2005.

2. Fottrell E, Kanhonou L, Goufodji S,et al Risk of psychological distress following severe obstetric complications in Benin: the role of economics, physical health and spousal abuse. Br J Psychiatry 2010;196:18-25.

3. van den Broek NR, Falconer AD. Maternal mortality and Millennium Development Goal 5. Br Med Bull 2011;99:25-38.

4. Kassebaum NJ, Bertozzi-Villa A, Coggeshall MS, et al. Global, regional, and national levels and causes of maternal mortality during 1990-2013: a systematic analysis for the Global Burden of Disease Study 2013. The Lancet 2014;384:980-1004.

5. Khan KS, Wojdyla D, Say L, et al. WHO analysis of causes of maternal death: a systematic review. Lancet 2006;367:1066-74.

6. Ononge S, Mirembe F, Wandabwa J, et al. Incidence and risk factors for postpartum hemorrhage in Uganda. Reprod Health 2016;13:38.

7. Rulisa S, Umuziranenge I, Small M, et al. et a/Maternal near miss and mortality in a tertiary care hospital in Rwanda. BMC Pregnancy Childbirth 2015;15:203.

8. Hutcheon JA, Lisonkova S, Joseph KS. Epidemiology of preeclampsia and the other hypertensive disorders of pregnancy. Best Pract Res Clin Obstet Gynaecol 2011;25:391-403.

9. Dolea C, AbouZahr C. Global burden of hypertensive disorders of pregnancy in the year 2000. WHO, 2003.

10. Abalos E, Cuesta C, Carroli G, et al. Pre-eclampsia, eclampsia and adverse maternal and perinatal outcomes: a secondary analysis of the World Health Organization Multicountry Survey on Maternal and Newborn Health. BJOG 2014;121 Suppl 1:14-24.

11. Dolea C, AbouZahr C. Global burden of obstructed labour in the year 2000. Evidence and Information for Policy World Health Organization, 2003.

12. Fantu S, Segni H, Alemseged F, Incidence AF. Incidence, causes and outcome of obstructed labor in jimma university specialized hospital. Ethiop J Health Sci 2010;20:145-51.

13. Kalisa R. Outcome of obstructed labor in Nort-west Rwanda, Unmatched Casa-control Study. American Journal of Public Health Research 2016;4:191-5.

14. Bucagu M, Kagubare JM, Basinga P, et al. Impact of health systems strengthening on coverage of maternal health services in Rwanda, 2000-2010: a systematic review. Reprod Health Matters 2012;20:50-61.

15. UN Economic Commission of Africa. MDG Report 2015: assessing Progress in Africa toward the Millennium Development Goals, 2015.

16. Rwanda National Institute of Statistics, Rwanda Ministry of Health, ICF International. Rwanda Demographic and Health Survey 20142015;2015;2015.

17. Bucagu M. Improving Maternal Health in Rwanda: the role of Community-Based interventions:. A Systematic Review J Community Med Health Educ 2016;6.

18. Manzi A, Munyaneza F, Mujawase F, et al. et alAssessing predictors of delayed antenatal care visits in Rwanda: a secondary analysis 
of Rwanda demographic and health survey 2010. BMC Pregnancy Childbirth 2014;14:290.

19. Rwanda Ministry of Health. Gynecology and Obstretics clinical protocols and treatment guidelines, 2012.

20. Rwanda Ministry of Health. Rwanda Annual Health Statistics Booklet 2014, 2015.

21. Nathan LM, Shi Q, Plewniak K, et al. Decentralizing Maternity Services to Increase Skilled Attendance at Birth and Antenatal Care Utilization in Rural Rwanda: A Prospective Cohort Study. Matern Child Health J 2015:19:1949-55.

22. Puri R, Rulisa S, Joharifard S, et al. Knowledge, attitudes, and practices in safe motherhood care among obstetric providers in Bugesera, Rwanda. Int J Gynaecol Obstet 2012;116:124-7.

23. Rwanda Ministry of Health. Rwanda Annual Health Statistics Booklet 2013, 2014.

24. Eichstaedt KE, Kovatch K, Maroof DA. A less conservative method to adjust for familywise error rate in neuropsychological research: the Holm's sequential Bonferroni procedure. NeuroRehabilitation 2013;32:693-6.

25. World Medical Association Declaration of Helsinki. Ethical principles for medical research involving human subjects. JAMA 2013;310:2191-4.

26. Mao L, Ma L, Liu N, et al. Self-reported health problems related to traditional dietary practices in postpartum women from urban, suburban and rural areas of Hubei province, China: the 'zuò yuèzi' . Asia Pac J Clin Nutr 2016;25:158-64.

27. Mwanri AW, Kinabo J, Ramaiya K, et al. Gestational diabetes mellitus in sub-Saharan Africa: systematic review and metaregression on prevalence and risk factors. Trop Med Int Health 2015;20:983-1002.

28. Atukunda EC, Siedner MJ, Obua C, et al. et alSublingual misoprostol versus intramuscular oxytocin for prevention of postpartum hemorrhage in Uganda: a double-blind randomized non-inferiority trial. PLoS Med 2014;11:e1001752.

29. Sayinzoga F, Bijlmakers L, van Dillen J, et al. et alMaternal death audit in Rwanda 2009-2013: a nationwide facility-based retrospective cohort study. BMJ Open 2016;6:e009734.

30. Ogwang S, Karyabakabo Z, Rutebemberwa E. Assessment of partogram use during labour in Rujumbura Health sub District, Rukungiri District, Uganda. Afr Health Sci 2009;9(Suppl 1):S27-34.
31. Mathai M. The partograph for the prevention of obstructed labor. Clin Obstet Gynecol 2009;52:256-69.

32. Berardi JC, Richard A, Djanhan Y, et al. Decentralization of maternity care. World Health Forum 1989;10:322-6.

33. Tebeu PM, Fomulu JN, Khaddaj S, et al. Risk factors for obstetric fistula: a clinical review. Int Urogynecol J 2012;23:387-94.

34. University of Rwanda College of Medicine and Health Sciences. Clinical officers training Programme at Kigali Health Institute Kigali, 2012. http://www.cmhs.ur.ac.rw/schools/community-healthdevelopment/clinical-madecine-community-health/ (accessed 12 Sep 2016).

35. Wilson A, Lissauer D, Thangaratinam S, et al. A comparison of clinical officers with medical doctors on outcomes of caesarean section in the developing world: meta-analysis of controlled studies. BMJ 2011;342:d2600.

36. Gibbons LBJ, Lauer J, Betran A, et al. The global numbers and costs of additionally needed and unnecessary caesarean sections performed per year: overuse as a barrier to Universal Coverage. World Health Report Background Paper 30, 2010.

37. Kiran A, Singh RR, Sinha AN, et al. A clinical study of 100 cases of Obstructed Labour and its Fetomaternal Outcome. Journal of Biology and Life Science 2015;6:141-7.

38. Malone FD, Geary M, Chelmow D, et al. et alProlonged labor in nulliparas: lessons from the active management of labor. Obstet Gynecol 1996;88:211-5.

39. Umubyeyi A, Mogren I, Ntaganira J, et al. et allntimate partner violence and its contribution to mental disorders in men and women in the post genocide Rwanda: findings from a population based study. BMC Psychiatry 2014;14:315.

40. Semasaka JP, Krantz G, Nzayirambaho M, et al. et alSelf-reported pregnancy-related health problems and self-rated health status in rwandan women postpartum: a population-based cross-sectional study. BMC Pregnancy Childbirth 2016;16:340.

41. Rwanda Ministry of Health. Guidelines for Researchers Intending to do Health Research in Rwanda. Kigali: Rwandan Ministry of Health, 2012.

42. Edvardsson $\mathrm{K}$, Ntaganira J, Åhman A, et al. et alPhysicians' experiences and views on the role of obstetric ultrasound in rural and urban Rwanda: a qualitative study. Trop Med Int Health 2016;21:895-906. 